\title{
Study of the effect of different type of aerosols on UV-B radiation from measurements during EARLINET
}

\author{
D. S. Balis ${ }^{1}$, V. Amiridis ${ }^{1}$, C. Zerefos ${ }^{2}$, A. Kazantzidis ${ }^{1}$, S. Kazadzis ${ }^{1}$, A. F. Bais ${ }^{1}$, C. Meleti ${ }^{1}$, E. Gerasopoulos ${ }^{1}$, \\ A. Papayannis ${ }^{3}$, V. Matthias ${ }^{4, *}$, H. Dier ${ }^{5}$, and M. O. Andreae ${ }^{6}$ \\ ${ }^{1}$ Laboratory of Atmospheric Physics, Aristotle University of Thessaloniki, 54006 Thessaloniki, Greece \\ ${ }^{2}$ Laboratory of Climatology and Atmospheric Environment, University of Athens, Greece and Foundation for Biomedical \\ Research of the Academy of Athens, Greece \\ ${ }^{3}$ National Technical University of Athens, Greece \\ ${ }^{4}$ Max Planck Institute for Meteorology, Hamburg, Germany \\ ${ }^{5}$ German Weather Service, Meteorological Observatory Lindenberg, Germany \\ ${ }^{6}$ Max Planck Institute for Chemistry, P.O. Box 3060, D-55020 Mainz, Germany \\ *now at: GKSS Research Center, Max-Planck-Strasse 1, 21502 Geesthacht, Germany
}

Received: 8 July 2003 - Published in Atmos. Chem. Phys. Discuss.: 2 September 2003

Revised: 24 December 2003 - Accepted: 23 January 2004 - Published: 17 February 2004

\begin{abstract}
Routine lidar measurements of the vertical distribution of the aerosol extinction coefficient and the extinctionto-backscatter ratio have been performed at Thessaloniki, Greece using a Raman lidar system in the frame of the EARLINET project since 2000. Co-located spectral and broadband solar UV-B irradiance measurements, as well as total ozone observations, were available whenever lidar measurements were obtained. From the available measurements several cases could be identified that allowed the study of the effect of different types of aerosol on the levels of the UV-B solar irradiance at the Earth's surface. The TUV radiative transfer model has been used to simulate the irradiance measurements, using total ozone and the lidar aerosol data as input. From the comparison of the model results with the measured spectra the effective single scattering albedo was determined using an iterative procedure, which has been verified against results from the 1998 Lindenberg Aerosol Characterization Experiment. It is shown that for the same aerosol optical depth and for the same total ozone values the UV-B irradiances at the Earth's surface can show differences up to $10 \%$, which can be attributed to differences in the aerosol type. It is shown that the combined use of the estimated single scattering albedo and of the measured extinction-to-backscatter ratio leads to a better characterization of the aerosol type probed.
\end{abstract}

Correspondence to: D. S. Balis

(balis@auth.gr)

\section{Introduction}

During the past decade there has been evidence for an increase of the biological active solar ultraviolet (UV-B) radiation reaching the earth's surface (e.g. Kerr and McElroy, 1993; Zerefos et al., 1997; Zerefos et al., 1998), as a consequence of the continuing negative trends in the stratospheric ozone concentration (WMO, 1998). However, there are still uncertainties in the UV trends since they are strongly affected by changes in the aerosol optical properties and changes in cloud cover (Zerefos et al., 2001; WMO, 2003). Due to the combined involvement of these parameters in controlling the UV-B levels it is difficult to determine accurately the role of each parameter, especially for urban sites, where UV-B reaching the boundary layer has a large diffuse component. Therefore it is more effectively absorbed by tropospheric ozone than the direct beam under high sun conditions (Brühl and Crutzen, 1989; Papayannis et al., 1998). Increases of the solar UV-B radiation may have a major effect on the environment (i.e. affect the ecosystem processes and biochemical cycles) and on humans (i.e. DNA damage, skin cancer, ocular effects) (Madronich, 1993). Additionally, a change in the UV-B solar radiation has direct effect on the chemical composition of the troposphere (e.g. Balis et al., 2002; Lantz et al., 1996; Shetter et al., 1996).

During the past few years various radiative transfer models have been developed (e.g. TUV, Madronich 1993 and the LibRadTran, Mayer et al., 1997), which offer various methods for the solution of the radiative transfer equation and allow the interpretation of the solar UV measurements. There 
are various studies which compare measured and calculated solar UV spectra. Recent studies by Kylling et al. (1997), Mayer (1997), and Kazantzidis et al. (2001) show that good agreement between measured and observed UV spectra can be achieved only if the input parameters are accurate and well defined. If this is the case, then the simulated spectra can agree within 5\% with the measurements. However at most stations where spectral UV measurements are available usually the only information available concerns the optical properties of the aerosols in the form of the aerosol optical depth (AOD) and its spectral dependence (Angström exponent). There are also a few cases, where the information about the physical properties of the aerosols (refractive index, size distribution) is also available from measurements, mainly from CIMEL sunphotometers.

The extinction to backscatter ratio, usually referred to as the lidar ratio, is a quantity that is directly measured by a Raman lidar (e.g. Ansmann et al., 1992) and the single scattering albedo (SSA) is one of the most dominant input factors that determine the aerosol type in a radiative transfer model (Kylling e al., 1998). Both depend on the microphysical properties of the aerosols and therefore their value can be used for the characterization of the aerosol type. Ferrare et al. (1998) used Raman lidar and aircraft size distribution measurements to derive estimates of the single scattering albedo. Their estimates showed that for similar humidity conditions, an increase in lidar ratio is accompanied by a decrease in SSA. As a consequence the same lidar ratios can correspond to different SSA values, under different humidity conditions. This fact indicates that the combined use of SSA and lidar ratio measurements will minimize the uncertainty in determining the aerosol type, necessary for the model calculations. Wenny et al. (1998) utilized a Miescattering code and a radiative transfer model in conjunction with measured parameters (transmission and size distribution measurements) to retrieve reasonable values of the single scattering albedo. Recently Kazantzidis et al. (2001) showed that there are indications for a high variability of the SSA even during the same day, which are correlated with changes in the wind direction and relative humidity. In this paper we study the effect of different types of aerosols on the levels of the solar UV-B radiation reaching the ground, by comparing measured and modeled spectral UV-B irradiances. As input we used aerosol extinction and lidar ratio vertical profiles, measured by a Raman lidar system, together with an indirect determination of the single scattering albedo, in the case where no measured information of the size distribution and chemical composition was available. First we present the instrumentation used in this study at Thessaloniki and Lindenberg. Next we briefly discuss the models used in the study, a radiative transfer model and an aerosol model for calculating optical properties. In the results and discussion section we show comparisons between UV-B measurements and calculations, where the need to determine the SSA is emphasized. The method used for the estimation of the SSA is applied on a day selected from the LACE-98 campaign. Then from the available UV-B measurements three cases are selected where by using the measured lidar ratio and the estimated SSA, as well as backward trajectories, we attempt to quantify the effect of different types of aerosols. Finally, we investigate the combined use of the directly measured lidar ratio, and the indirectly estimated SSA, that allow a better characterization of the aerosols, using remote sensing techniques.

\section{Data and methodology}

\subsection{Experimental data}

At the Thessaloniki station $\left(40.5^{\circ} \mathrm{N}, 22.9^{\circ} \mathrm{E}\right)$ two Brewer UV spectrophotometers, one single and one double monochromator, operate continuously and monitor nearly the whole UV-B solar spectrum from $290-325 \mathrm{~nm}$ and $290-$ $366 \mathrm{~nm}$ respectively with a $0.5 \mathrm{~nm}$ spectral resolution. The calibration of the instruments is performed using a $1000 \mathrm{~W}$ lamp, a source with output irradiance traceable to the National Institute of Standards and Technology standards every month. The stability of the instruments is monitored in the field by a set of $50 \mathrm{~W}$ lamps, once a week. In addition, measurements of global (direct and diffuse) erythemal irradiance are being performed (Zerefos et al., 1998). $\mathrm{O}_{3}$ and $\mathrm{SO}_{2}$ total columns, also determined from the Brewer spectrophotometer, have been used to provide input to the model calculations. A similar single Brewer monochromator for monitoring total ozone and spectral UV measurements of global irradiance operates continuously at Lindenberg $\left(52.21^{\circ} \mathrm{N}\right.$, $\left.14.12^{\circ} \mathrm{E}\right)$, Germany. For the determination of the AOD at Thessaloniki we used, depending on the availability of the data, two data sources. We used AOD values at $355 \mathrm{~nm}$ directly estimated from calibrated direct irradiance spectra by the Brewer spectrophotometer (Marenco et al., 1997) as well AOD values at $416 \mathrm{~nm}$ (extrapolated to $355 \mathrm{~nm}$ using the corresponding Angström exponent) estimated by a multifilter shadowband radiometer (MFR-7, Yankee Environmental System Inc., Turner Falls, Massachusetts also operating at Thessaloniki (Gerasopoulos et al., 2003). The filter radiometer provides 1-min average AOD at five wavelengths (415, $501,615,675$ and $867 \mathrm{~nm}$ ). A detailed description of the operation principles of the MFR can be found in Harrison et al. (1994).

The lidar system of the Laboratory of Atmospheric Physics (LAP) was designed to perform continuous measurements of suspended aerosols particles in the Planetary Boundary Layer (PBL) and the lower free troposphere (Papayannis and Balis, 1998; Balis et al., 2000,). It is based on the second and third harmonic frequency of a compact, pulsed Nd:YAG laser, which emits pulses of 300 and $120 \mathrm{~mJ}$ output energy at $532 \mathrm{~nm}$ and $355 \mathrm{~nm}$, respectively, with a $10 \mathrm{~Hz}$ repetition rate. The optical receiver is a $500 \mathrm{~mm}$ diameter telescope (with a 1-3 mrad adjustable field-of-view). 
Since mid-2000 in the frame of the European Aerosol Research Lidar Network (EARLINET) (Bösenberg et al., 2001) the system was upgraded to a Raman lidar and now three photomultipliers (Hamamatsu 5600P-06) are used to detect the lidar signals at 532, 355 and $387 \mathrm{~nm}$ respectively. The acquisition system is based on a three-channel LICEL Transient Digitiser working on both the analogue (12-bits, $40 \mathrm{MHz}$ ) and the photon counting (250 MHz, 8192 bins) modes. Using the methodology proposed by Ansmann et al. (1992) the measurement of the elastic-backscatter signal at $355 \mathrm{~nm}$ and of the nitrogen inelastic-backscatter signal at $387 \mathrm{~nm}$ permits the determination of the extinction and backscatter coefficients independently of each other and, thus, of the extinction- to-backscatter ratio also called lidar ratio (LR). For each extinction profile a large number of laser shots is averaged (usually over 30000 laser shots) and the resulting signal profile is smoothed. The Raman technique also requires measurements of the atmospheric density, which is computed from pressure and temperature profiles measured by radiosondes, launched at the Thessaloniki airport. The height profile of the particle backscatter coefficient at 355 $\mathrm{nm}$ is determined from the ratio of the elastic to the inelastic nitrogen Raman signal and the extinction-to-backscatter ratio is then calculated. An overlap correction is applied to the results, only down to $800 \mathrm{~m}$, as suggested by the iterative technique proposed by Wandinger and Ansmann (2001). The lidar system of LAP and the algorithms implemented were successfully intercompared within EARLINET (Matthias et al., 2004).

For the determination of the AOD at Lindenberg we used measurements performed with a multiwavelength sunphotometer, that is routinely operated by the German Weather Service (DWD). In our analysis we used measurements at 399 and $451 \mathrm{~nm}$ and the corresponding Angstrom exponent in order to estimate the AOD at $323 \mathrm{~nm}$. A detailed description of the instrument and its quality assurance and control is discussed in detail by Leiterer et al. (1994). The sunphotometer is regularly calibrated at mountain sites using the Langley plot technique. The absolute accuracy of the measured optical thickness is estimated to be \pm 0.02 . To observe the daily evolution of the aerosol loading for the day considered in this study we used backscatter profiles at $320 \mathrm{~nm}$ from the MPI UV lidar in KrF operation, using a grating spectrometer for the wavelength separation. The MPI UV lidar is described in detail by Matthias (2000).

Backward trajectories at certain pressure levels in the troposphere were provided in the frame of EARLINET by the DWD and were used to determine the origin of the aerosols observed.

\subsection{Modeling tools}

In this study, we run the Tropospheric Ultraviolet and Visible model (TUV-version 4.0, Madronich, 1993) version 4.0 using the pseudospherical DISORT which was run using 16 streams (Stamnes et al., 1988). Irradiance spectra were calculated in $0.015 \mathrm{~nm}$ steps, convoluted with the slit function of the Brewer and sampled at intervals of $0.5 \mathrm{~nm}$ to match the measurements. By comparing the modelled with the measured spectra, the effective single scattering albedo was determined using an iterative methodology proposed recently by Bais et al. (2002, 2003).

For the theoretical determination of the aerosol optical properties that are relevant to the transmission of the UV$B$ radiation through the atmosphere we used the software OPAC (Optical Properties of Aerosols and Clouds). This model provides optical properties in the solar and terrestrial spectral range of atmospheric particulate matter (Hess et al., 1998), Microphysical and optical properties of 6 water clouds, three ice clouds and 10 aerosol types are considered as typical cases. The optical properties of the aerosol particles considered in this study were the extinction, scattering and absorption coefficients, the single scattering albedo and the lidar ratio at $355 \mathrm{~nm}$. These are calculated on the basis of the microphysical data (size distribution and spectral refractive index) under the assumption of spherical particles in the case of aerosols.

\subsection{Methodology for the estimation of the SSA}

To derive estimates of the effective SSA on cloud-free days with different aerosol conditions, we used measured spectral irradiances and aerosol optical depths at the stations of Thessaloniki and Lindenberg. Measurements of global and diffuse (the latter available only at Thessaloniki) irradiance and of direct-to-diffuse irradiances ratio were compared with model calculations, which were based on the actually measured total ozone column and aerosol optical depth. As input to the model calculation we used the nearest in time (usually within one hour) to the measured spectrum aerosol optical depth and total ozone, from the instruments described in the previous paragraph, assuming that the aerosol and ozone conditions remained rather stable during a period of two hours in the late afternoon. Concerning total ozone at Lindenberg only daily average values were available. The surface albedo was assumed in both cases 0.03 .

The solar zenith angle for which the calculations were performed corresponded to the actual solar zenith angle at which the irradiance at $323 \mathrm{~nm}$ (at Lindenberg) and $355 \mathrm{~nm}$ (at Thessaloniki) was measured. The spectral data used for comparison with the model calculations were first cosine corrected. From these comparisons we determined the values of SSA for which the model and the measurements were in agreement to better than $1 \%$. Depending on the sensitivity of each quantity to changes in SSA, more than one value of the SSA may satisfy the above condition. The average of these values is considered as the effective single scattering albedo. It was considered meaningless to assume a higher precision than 0.01 for the SSA. It appears that all three methods give less uncertain results in cases with high aerosol contents. The 


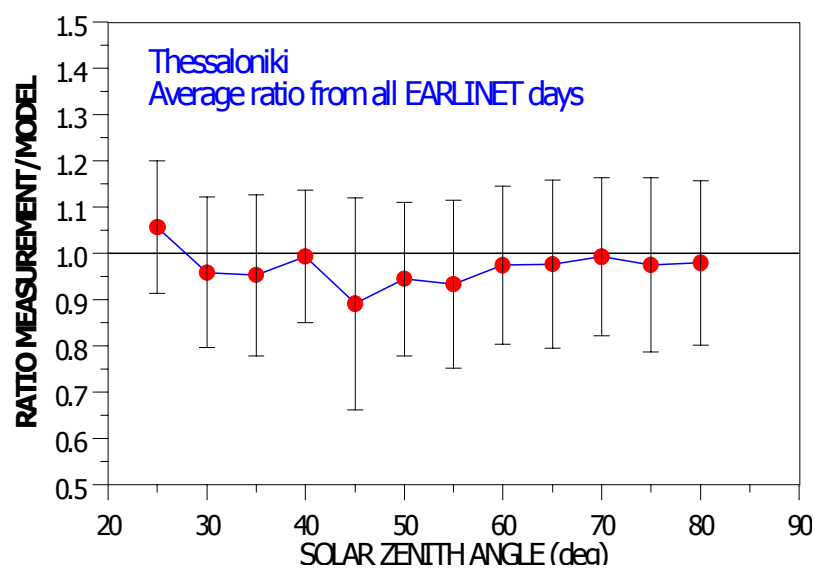

Fig. 1. Ratio of measured to modeled erythemal irradiance as a function of solar zenith angle for Thessaloniki, Greece.

individual uncertainties of the measurements, modeling and aerosol optical depth determination contribute to the overall uncertainty in determining the SSA and are discussed in detail by Bais et al. (2003). The achievable accuracy in estimating the SSA depends on the zenith angle, the aerosol optical depth (here we use AOD at $355 \mathrm{~nm}$ ) and the radiation quantity used. When using the direct-to-diffuse ratio it is \pm 0.06 for $\mathrm{AOD}=0.2$ and \pm 0.04 for $\mathrm{AOD}=0.4$ both at small and large zenith angles. When using the global irradiance the achieved accuracy for small zenith angles is \pm 0.15 for $\mathrm{AOD}=0.2$ and \pm 0.08 for $\mathrm{AOD}=0.4$. For large zenith angles, usually used in this study, it is \pm 0.13 for $\mathrm{AOD}=0.2$ and \pm 0.05 for $\mathrm{AOD}=0.4$ (Bais et al., 2003). These accuracy estimates are comparable with accuracy levels reported from relevant studies (Petters et al., 2003; Dubovik et al., 2000) and impose some limitations to the use of such methods of indirect determination of SSA under low aerosol conditions. It has to be emphasized that even a difference of 0.1 in SSA is substantial in terms of the interaction with radiation (e.g. Weihs and Webb, 1997)

\section{Results and discussion}

3.1 Comparison between model calculations and UV irradiance measurements. The importance of the single scattering albedo

All spectral measurements performed at Thessaloniki during the days when lidar measurements were available, were compared with model calculations using as input the total ozone measured by the Brewer spectrophotometer and the aerosol optical depth at $355 \mathrm{~nm}$ measured with the Brewer (Marenco et al., 1997) while the shape of the aerosol extinction profile was adopted by the nearest in time lidar profile, assuming that there are background aerosol conditions in the stratosphere. For the selection of the SSA a pre-calculated value of 0.8 was used initially, corresponding to a realistic assump- tion concerning the microphysical properties of the aerosols of an urban site (Shettle and Fenn, 1979). In total we calculated the erythemal irradiance for various zenith angles for 35 clear sky days during the years 2000-2001. The resulting ratios of the measurements of the erythemal irradiance over the calculations were binned over $5^{\circ}$ solar zenith angle intervals. These average ratios and their respective standard deviations are shown in Fig. 1. As it is clear from this figure the mean ratio is of the order of 0.98 and does not show any solar zenith angle dependence, since the pseudospherical DISORT was used for the model calculations. This mean ratio indicates that in general the model simulates well the measured UV irradiance, when total ozone and aerosol optical depth are accurately known. However, as it is indicated from the standard deviation of the ratios, the uncertainty in the choice of the appropriate SSA value, introduces maximum differences of about $20 \%$ for individual simulations, performed for all the clear sky days during EARLINET, when both UV and lidar measurements were available. This uncertainty is significant and limits our ability to use a radiative transfer model for the interpretation of the UV measurements for an area that can be influenced by various aerosol sources and aerosol types. Thessaloniki is a crossroad where aerosol can be transported form Central and Eastern Europe (e.g. Eisinger and Burrows, 1998; Zerefos et al., 2000; Formenti et al., 2001), from the Atlantic Ocean, from the Western Mediterranean and from the Sahara desert (e.g. Balis et al., 2003; Lelieveld et al., 2002). For this reason we applied in this paper an indirect method for estimating the single scattering albedo, which has already been described in the previous section.

3.2 Verification of the methodology for the estimation of the SSA using LACE98 data

We applied the iterative procedure for the indirect determination of the single scattering albedo on a case extracted from the LACE98 experiment (Ansmann et al., 2002). We used cosine corrected global irradiance measurements performed with a single Brewer at Lindenberg and aerosol optical depth measurements at $323 \mathrm{~nm}$ extrapolated from measurements at $399 \mathrm{~nm}$ performed with the sunphotometer during 10 August 1998, a cloud free day. Additional measurements performed on that day allow the justification of the estimated SSA values. In Fig. 2a we show the application of the method on the measurements of that day. As it is evident from that figure there is variability during the day in the values of SSA that give ratios close to 1 . In the morning hours the method indicates values larger than 0.9 while in the afternoon the SSA values decrease even down to 0.6 . This change indicates different optical properties of the aerosols above the measuring site between the morning and the afternoon hours.

The daily course of the aerosol optical depth at $323 \mathrm{~nm}$ is also shown in Fig. 2a. It peaks around local noon with values close to 0.2 and decreases down to 0.12 , late in the afternoon. Based on the discussion of section 2.3 the accuracy of the 


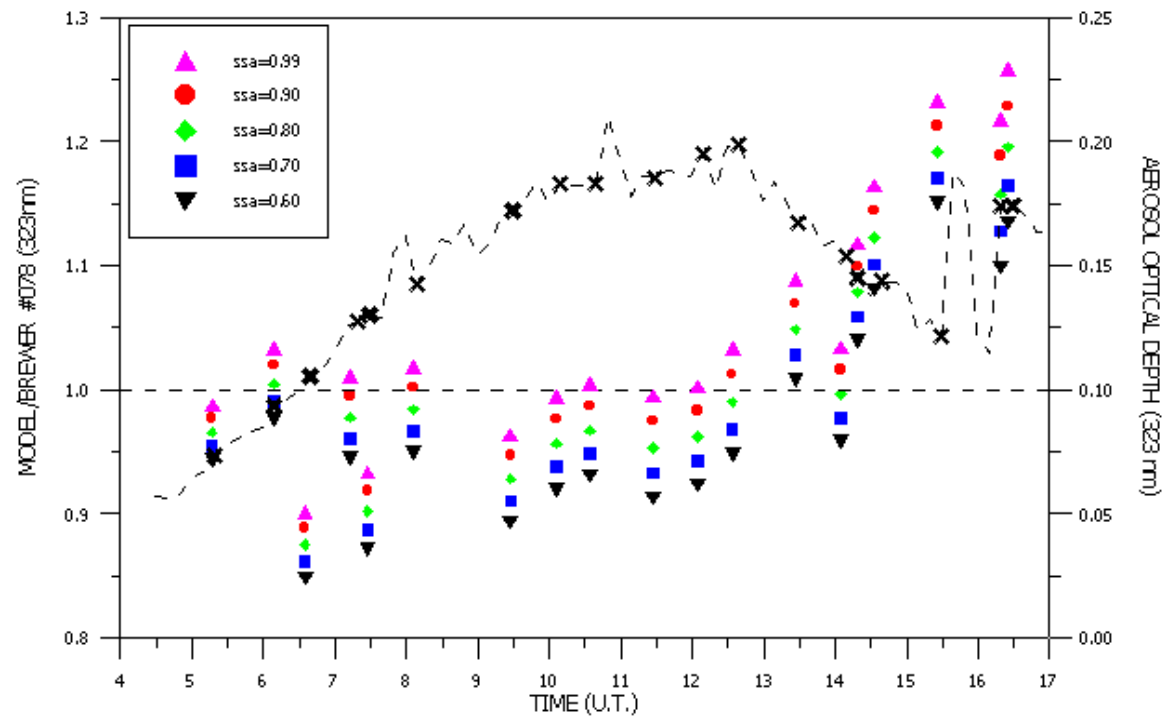

Fig. 2a. Ratio of modeled to measured irradiance at $323 \mathrm{~nm}$ for 10 August 1998 at Lindenberg Germany, for the SSA values indicated and $\mathrm{AOD}$ at $323 \mathrm{~nm}$.

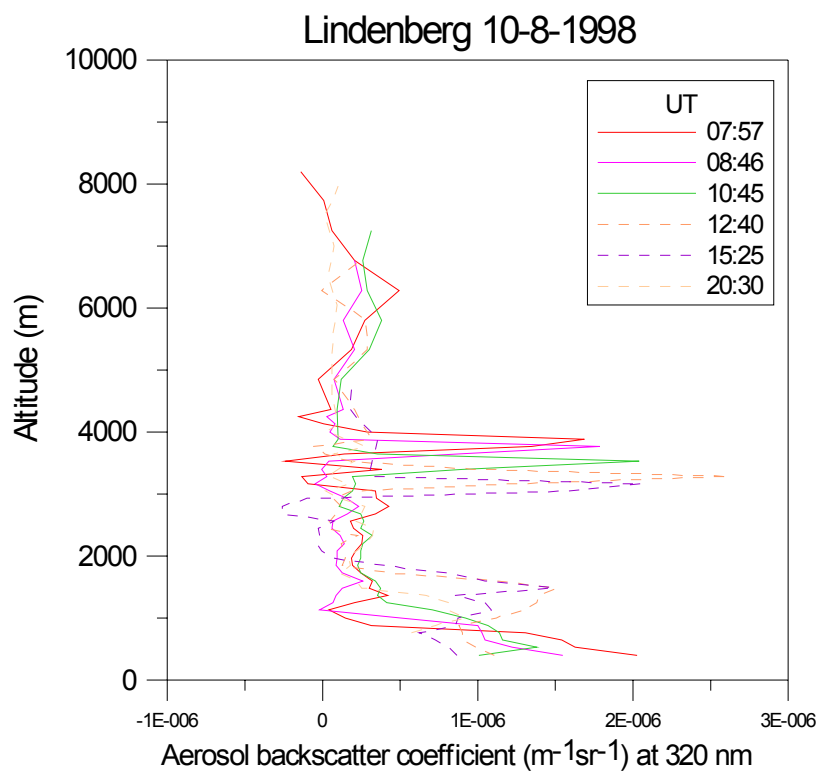

Fig. 2b. Daily evolution of the aerosol backscattering coefficient at $320 \mathrm{~nm}$ measured with the MPI UV lidar at Lindenberg for 10 August 1998.

estimated SSA values lies in the range \pm 0.13 and \pm 0.05 , between 9:00 and 14:00 UT depending mostly on the observed AOD values, i.e. the SSA estimates are less accurate in the afternoon when AOD decreases. There are also cases during that day that do not have ratios close to 1 , for any SSA value. Probably for these cases the input parameters do not represent correctly the atmospheric conditions during the spectral

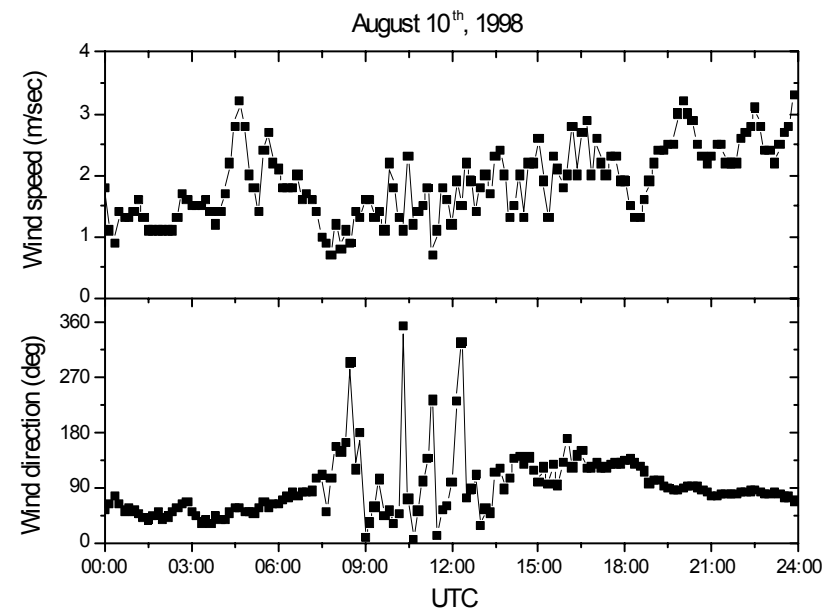

Fig. 2c. Wind speed and wind direction measurements for $10 \mathrm{Au}-$ gust 1998 at Lindenberg.

measurements (e.g. existence of sharp aerosol layers, broken clouds etc). As described in Ansmann et al. (2002) the flow was from the north-north east during most of that day with low aerosol optical depth values. As it shown in Fig. 2c in the afternoon after 13:30 UT the winds changed to easterlies, indicating the arrival over the measuring site of air masses that contain aerosols with different optical properties, which could also correspond to more absorbing aerosols.

The lidar data (Fig. 2b) show an increase of the aerosol backscatter with height in the lowest $2 \mathrm{~km}$ in the afternoon hours relative to the morning hours. The elevated aerosol layer observed on this day between 3 and $4 \mathrm{~km}$ is slowly 
decreasing with height without any change in optical depth. The increase in the optical depth in the boundary layer is clearly connected with an increase in the boundary layer height. However, the change in wind direction indicates an influence of aerosols from other sources on the total optical depth. Aerosols from urban regions are more absorbing in the UV (e.g. Shettle and Fenn, 1979) and therefore these smaller values of the SSA might be attributed to a slow transport of urban aerosols over the measuring site, considering the moderate wind speed and the relatively low AOD values observed after the change in the wind direction. Changes in the SSA could also be attributed to changes in the relative humidity, since dryer aerosols correspond to smaller SSA values.

Bundke et al. (2002) show time series of SSA for the whole LACE98 period, based on two approaches, the one is based on PSAP absorption measurements and nephelometer measurements and the second is based on photometer measurements using the inversion algorithm by Haenel et al. (1994). The latter provides an estimate of 0.85 , without allowing however to distinguish between morning and afternoon values. The first technique reports small SSA values throughout the day, possibly because it is affected mostly by the aerosols close to the Earth's surface. Hoyningen-Huene et al. (2001) report for the same day an SSA value of 0.92 to 0.85 depending on the methodology used.

\subsection{Case studies with different aerosol types}

Beneath the available UV and lidar measurements at Thessaloniki we identified some clear sky cases that allow the effect of the different aerosol properties on the solar UV levels at the Earth's surface to be quantified. For this purpose we used the total ozone measurements and the aerosol optical depth measurements performed with the double Brewer spectroradiometer, the estimated SSA, profiles of the aerosol extinction coefficient and the lidar ratio, as well as backward trajectories. Since the Raman lidar measurements are performed only after sunset we examined here only spectral measurements performed during late the afternoon hours in order to minimize the time difference between the two measurements. Comparisons were performed between measurements that correspond to the same solar zenith angle. We have to emphasize here that the mean lidar ratio, due to the system's overlap function, does not take into account the first $800 \mathrm{~m}$, while the effective SSA is heavily influenced by this layer (which contains most of the urban aerosol) and thus under polluted conditions at the surface, these two parameters might not represent similar aerosol conditions.

From all the available spectral UV measurements we selected three cases to study in more detail, which, according to the aerosol lidar measurements and to the trajectory analysis, corresponded to distinct aerosol conditions. These three cases were selected from the period September-October 2001. Figure 3 presents the total ozone measurements and the measurements of the global irradiance at $305 \mathrm{~nm}$ for the period of these two months. At this wavelength the absorption by ozone is very strong with a Radiation Amplification Factor (RAF) of about 3 (Bais et al., 1993) while the accuracy of the measurements is better than $5 \%$. The solid circles show the measured values of the UV irradiance, while the diamonds show the modeled values considering only the effect of ozone absorption in the calculations. The differences between the two curves show the effect of the aerosols on the attenuation of UV irradiance at the surface. It is evident from this figure that day-to-day changes in the aerosol optical properties can cause changes in the UV of similar magnitude with those induced from the variability in the total ozone column. As shown in the figure, this effect is on the average about $4 \%$ but there are days when the aerosol effect can reach almost 30\%. Kylling et al. (1998) found similar cases in spectral UV measurements performed on a remote island in the Northern Aegean Sea during the PAUR experiment that took place in 1996. Balis et al. (2002) showed that under certain aerosol conditions (high load of absorbing aerosols and high values of tropospheric ozone) a decrease of $50 \mathrm{DU}$ in total ozone, associated with transport from the extratropics and accompanied by substantial increase of the aerosol optical depth (due to Sahara dust) can even lead to a decrease in UV radiation, which means that the high aerosol load masks the expected increase due the total ozone decrease. From this two-month period we will present in more detail the following three cases, according to the trajectories they allow a distinct characterization of the air masses present over the measuring site:

- Case 1: A Saharan dust event versus a dust free aerosol case with (25 September 2001 versus 17 September 2001).

- Case 2: Two days with same total ozone and same aerosol optical depth but with different lidar ratio and UV irradiance (13 September 2001 versus 29 October 2001).

- Case 3: A pollution episode, where the total ozone decline is accompanied by a decrease in UV irradiance, compared with a cleaner case (11 October 2001 versus 4 October 2001).

Case 1: Coordinated lidar measurements of Saharan dust particles were very frequent during the EARLINET project and provided detailed information concerning the characteristics and evolution of such events. Many of these events reached also Thessaloniki, however during few of them clear sky UV observations were also possible. According to theoretical calculations by Ackermann et al. (1998) desert dust particles are characterized by LR of about $40 \mathrm{sr}$. Because the particles are not hygroscopic, the lidar ratio is not very sensitive to changes in relative to humidity. Mattis et al. (2002) presented lidar ratio profiles at both $355 \mathrm{~nm}$ and $532 \mathrm{~nm}$ corresponding to Saharan dust indicating that also larger lidar 


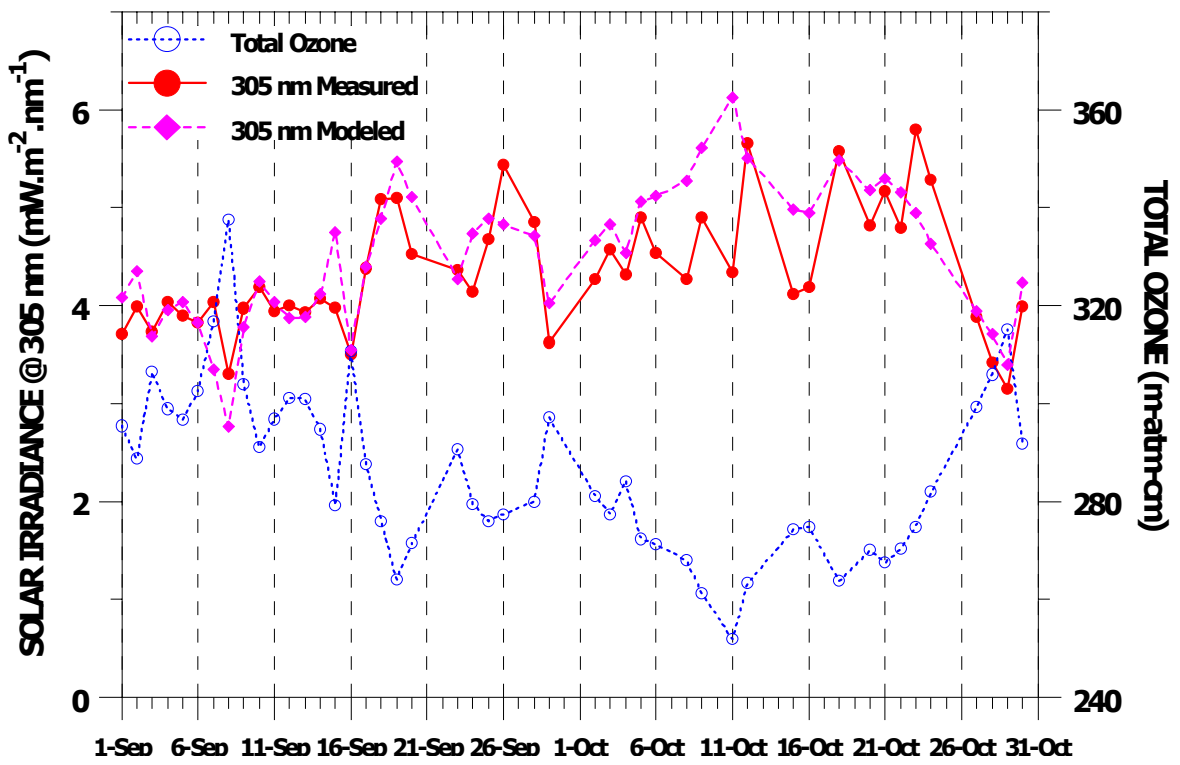

Fig. 3. Total ozone and global UV irradiance measurements at Thessaloniki, Greece for the period Sep-Oct 2001.

ratio values can be expected by a combined effect of long range transport and non-spherical shape of the dust particles. It is evident from the trajectory analysis in Fig. 4 that on 25 September the air masses between $850 \mathrm{hPa}$ and $500 \mathrm{hPa}$ originated from the Sahara desert. As a consequence the profile of the lidar ratio is uniform in this layer with values slightly exceeding $30 \mathrm{sr}$, which are rather consistent with the theoretical estimations. The Saharan dust particles show larger absorption in the UV (e.g. Balis et al., 2002; di Sarra et al., 2002) and therefore can attenuate the UV radiation reaching the Earth's surface. We compared the UV irradiance at $305 \mathrm{~nm}$ with the measurements performed on 17 September 2001 when ozone levels were similar but according to the trajectory analysis, also shown in Fig. 5, the particles present above the measuring site must have resulted from a mixture of maritime and continental aerosols, which lead to small lidar ratio values of about $20 \mathrm{sr}$, that indicate low absorbing particles. The UV irradiance during the Sahara dust event is almost 5\% lower than the one during the other day, after removing the contribution to the difference that are attributed to the small total ozone difference between these two days. The estimated SSA values are 0.83 and 0.89 respectively, which are consistent with the lidar ratio profiles and the trajectory analysis.

Case 2: The interesting feature of case 12 is that both total ozone and aerosol optical depth were almost the same during these measurement periods although under clear sky conditions the UV levels differed by $10 \%$. In Fig. 5 the extinction and lidar ratio profiles for both days are presented. As shown in this figure the profile of the aerosol extinction coefficient (as measured with the Raman lidar), the aerosol optical depth and the total ozone amount are similar. However there are large differences in the profile of the lidar ratio, indicating that the microphysical parameters of the aerosol present above the measuring site are different between these two days. On 13 September the profile of the lidar ratio above $800 \mathrm{~m}$ showed values of about $20 \mathrm{sr}$ which correspond to particles with relatively large maritime component (e.g. Ackerman et al., 1998), which is supported by the trajectories analysis for that day. On 29 October the lidar ratio values were larger than 70 indicating the presence of more absorbing aerosols, originating from central and NE Europe. This difference is demonstrated also in the levels of the UV-B irradiance, since the day with small lidar ratio the UV-B levels were higher. The estimated SSA values for these two days are shown in Table 1 and are respectively 0.77 and 0.87 indicating more absorbing aerosols during the day with "maritime" particles, which is not consistent with the lidar ratio measurements and the observed UV levels. We suggest that most of this inconsistency should be attributed to the uncertainty of the SSA estimates, as it has been discussed in Sect. 2.3, which is highly dependent on the uncertainty in the measured radiometric quantities.

Case 3: The 11th of October was characterized by low total ozone values (252 DU) and high aerosol optical depth, as can be seen in Fig. 6. According to the trajectories the air masses within the $0-3 \mathrm{~km}$ layer originated mostly from the Balkans and Italy, indicating the presence of polluted air masses, with significant maritime component. On 4 October total ozone was higher, and the trajectories indicated the presence of polluted air masses of rather local origin (Balkans, Black Sea and Turkey), while large-scale subsidence transported cleaner air from higher layers downwards, resulting to smaller aerosol optical depth. This means that 
Table 1. Effective SSA and mean lidar ratio for cases selected from the EARLINET database.

\begin{tabular}{ccccccc}
\hline Date & Remarks & Ozone [DU] & AOD & Effective SSA & Mean LR [sr] & UV attenuation \\
\hline $25-9-2001$ & Sahara dust & 275 & 0.55 & 0.83 & 30 & $5 \%$ \\
$17-9-2001$ & Dust free & 287 & 0.52 & 0.89 & 10 & 10 \\
$13-9-2001$ & Same TOZ & 301 & 0.43 & 0.77 & 80 & $10 \%$ \\
$29-10-2001$ & Same AOD & 305 & 0.44 & 0.87 & 60 & $25 \%$ \\
$11-10-2001$ & High AOD & 252 & 0.66 & 0.85 & 75 & \\
$4-10-2001$ & Low AOD & 284 & 0.33 & 0.88 & \\
\hline
\end{tabular}

we expect in both cases similar aerosol types with significantly different aerosol optical depth. The lidar ratio values measured were relatively high ( $>60 \mathrm{sr}$ ) and can be attributed to aerosols originating from polluted regions in both cases. Also the estimated values of the SSA for both days (0.85) are similar. Although total ozone was lower on the 11th of October compared to the 4th the UV irradiance at $305 \mathrm{~nm}$ was almost identical, which means that the high aerosol optical depth observed during this day causes a reduction of about $30 \%$ in UV irradiance, which masks the increase in the UV irradiance expected due to the decrease of about $30 \mathrm{DU}$ in total ozone (about 10\% decrease). The existence of such cases in polluted urban regions can be very frequent and therefore their knowledge is very important for correct interpretation of UV trends in such regions (e.g. Zerefos et al., 1998). The main results of these three cases are summarized in Table 1.

\subsection{Relation between lidar ratio and effective single scat-} tering albedo

The three cases discussed above made it possible to quantify the effect of certain types of aerosol on the UV irradiance but it also left many uncertainties about the consistency between the measured lidar ratio profiles and the estimated SSA values. Therefore selected clear sky spectral measurements of global and diffuse irradiance and of direct-to-diffuse irradiance ratio from the days considered in Fig. 1 were compared with model calculations, which were based on the actually measured total ozone column and aerosol optical depth. From these comparisons we estimated the values of SSA for which the model and the measurements were in agreement to better than $1 \%$. As discussed before, the mean of the values that satisfied the above limit, was considered as the effective single-scattering albedo of the layer above the measuring site. For the same cases we calculated the mean lidar ratio as determined by the nearest in time measurement with the Raman lidar of LAP, for the $0.8-5 \mathrm{~km}$ layer. From the days considered in Fig. 1, only for 18 cases it was possible to have both SSA and LR estimates under clear skies. The estimates for these cases are shown in Fig. 7. For comparison purposes we also calculated with OPAC theoretical estimates for the SSA and the lidar ratio at $355 \mathrm{~nm}$ that represent various aerosol models and relative humidity classes. The aerosol types considered are continental (clean, average, polluted), urban, desert and maritime (clean, polluted, tropical). For each aerosol type we calculated SSA and LR values for 5 relative humidity classes that are considered frequent for Thessaloniki (50, 70, 80, 90, 95\%). These calculations are demonstrated in Fig. 8. From both figures it is evident that similar SSA or LR values can correspond to different aerosol types and thus it is not possible to strongly correlate these air mass type based on trajectories. However the simultaneous knowledge of both parameters improves our ability to characterize the aerosol type. For instance SSA values of 0.9 can correspond to both maritime and continental aerosols, which however have different LR values. Similarly urban and continental aerosols might have similar LR values but different SSA values. The comparison of the two figures indicates that the experimental determination of the SSA and the lidar ratio are consistent with the OPAC estimations for the cases where according to the trajectories one expects larger maritime component and for the cases where aerosol are considered as continental mostly of local origin. These are highlighted as maritime and continental in Fig. 7. For these cases the estimated SSA values are slightly lower than the theoretical ones, indicating an impact of the aerosol present near the surface. According to the trajectories these cases include also events with desert particles, which are mixed with maritime aerosols from the Mediterranean. There is a group of points in Fig. 7 that according to the estimated SSA should be representative of urban aerosols, but they correspond to relatively low lidar ratio values, which can be found for maritime particles. The latter is consistent with the trajectories that correspond to these points. When examining the profiles of the backscattering coefficient at $532 \mathrm{~nm}$, which can be used from $400 \mathrm{~m}$ upward, they indicate that for these cases the aerosol loading closer to the surface is much higher compared to the well defined cases, but unfortunately no lidar ratio values can be calculated for this altitude range. The high aerosol load close to the surface is usually associated with urban activities and this fact can explain the low SSA values. It indicates that in case of vertical inhomogeneity of the aerosol type the effective SSA is not representative for the whole aerosol column. For all these cases we have again to stress that the SSA and LR estimates might have a time difference of maximum two hours and so they might be affected also by rapid 


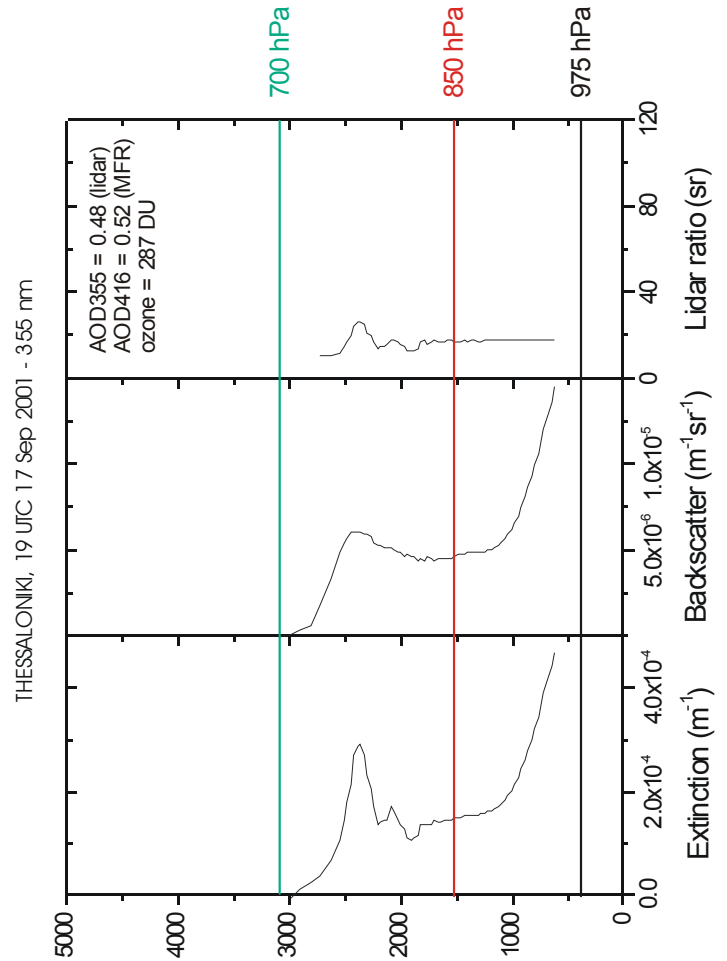

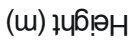

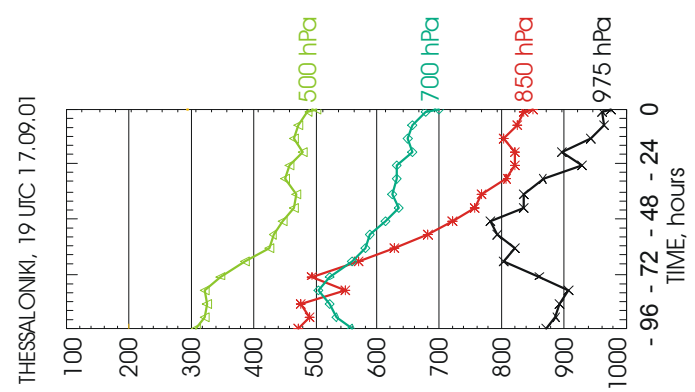

Ddu ' $\exists$ dInSS

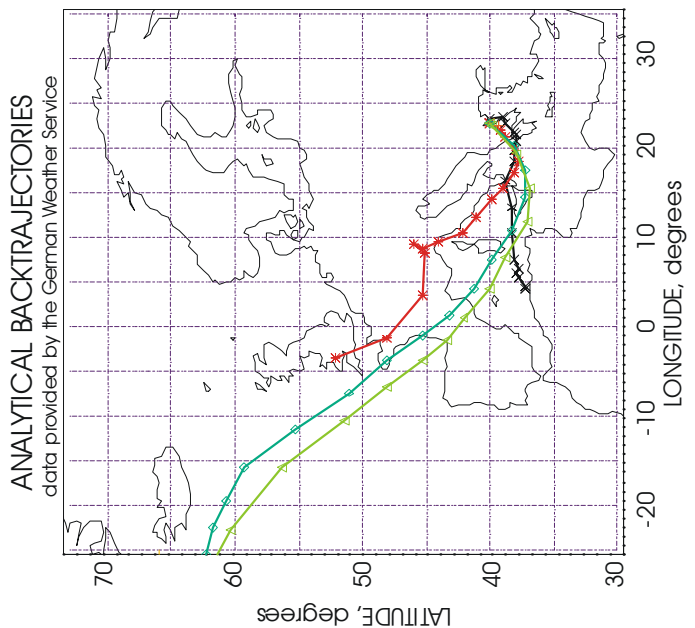

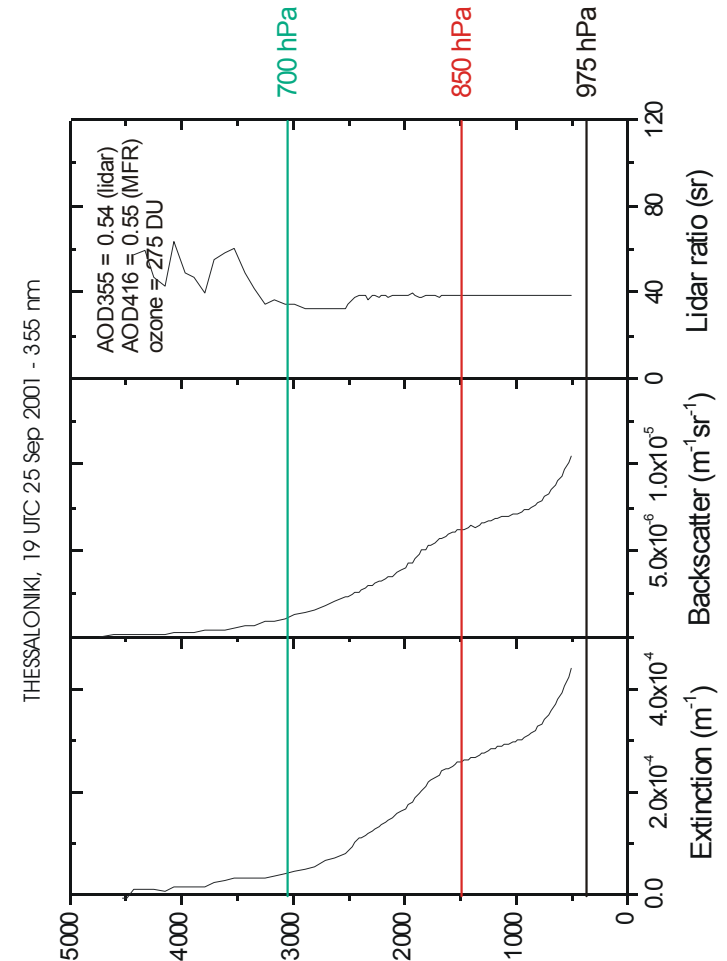

(u) ㄴㅣㅟㅂ
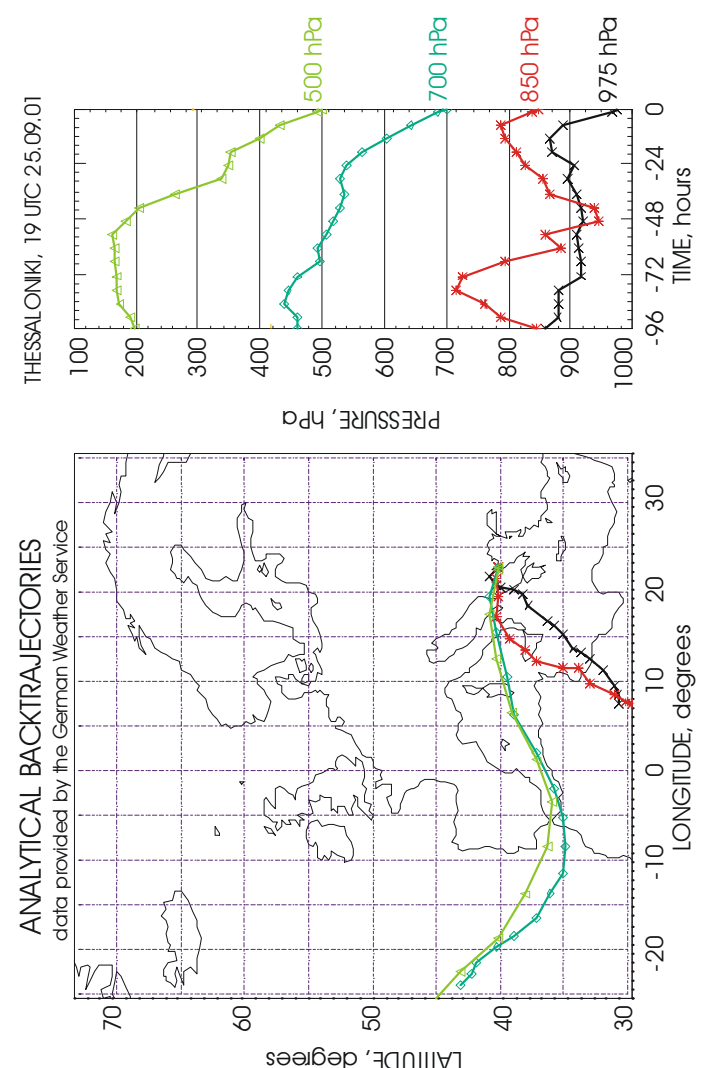

Fig. 4. Profiles of aerosol extinction coefficient, aerosol backscatter coefficient and lidar-ratio measured at Thessaloniki with the corresponding backward air trajectories calculated from the DWD for 25-9-2001 and 17-9-2001. 


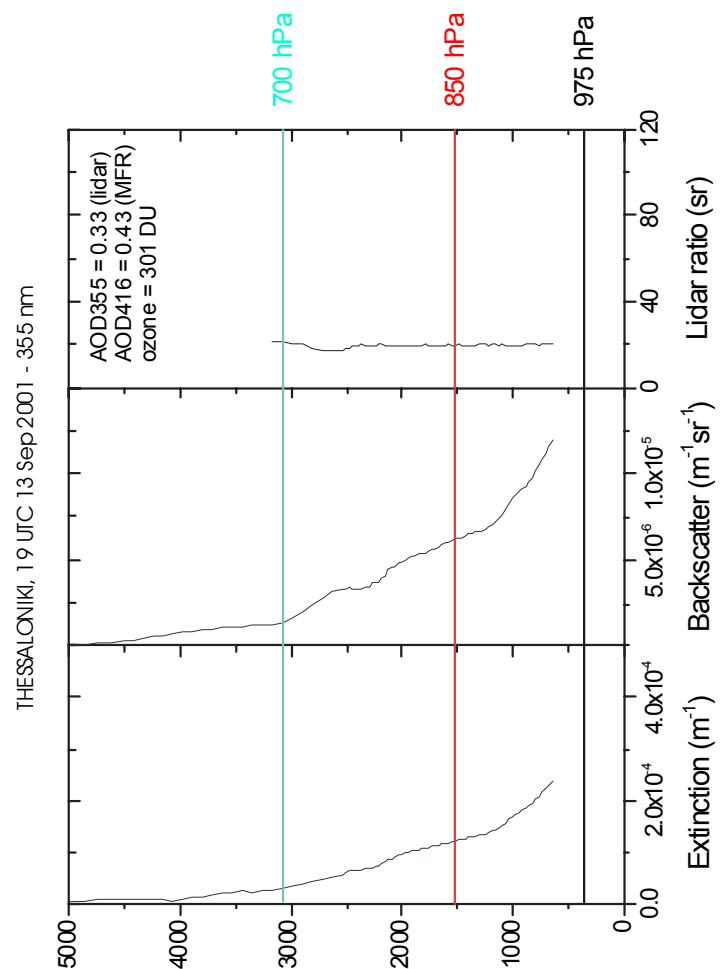

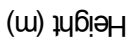

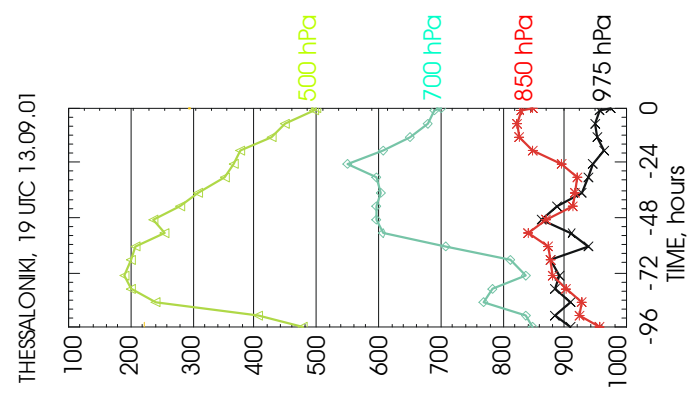

Ddu ' $\exists$ Junstady

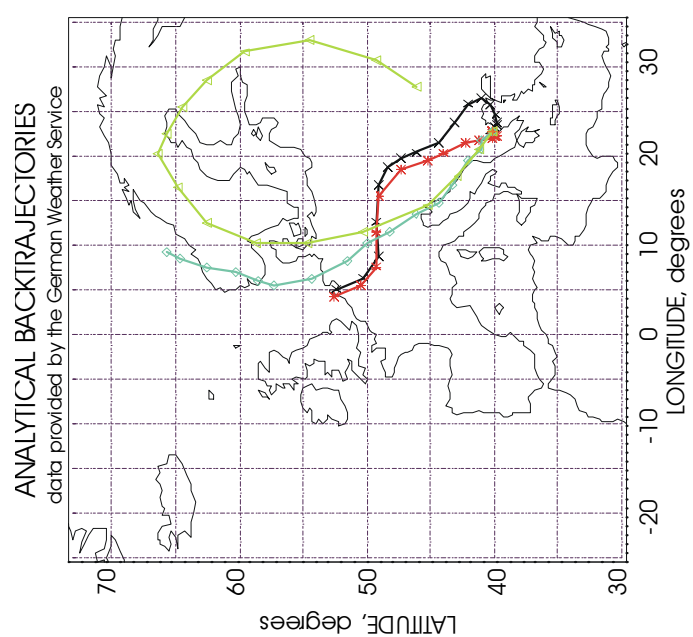

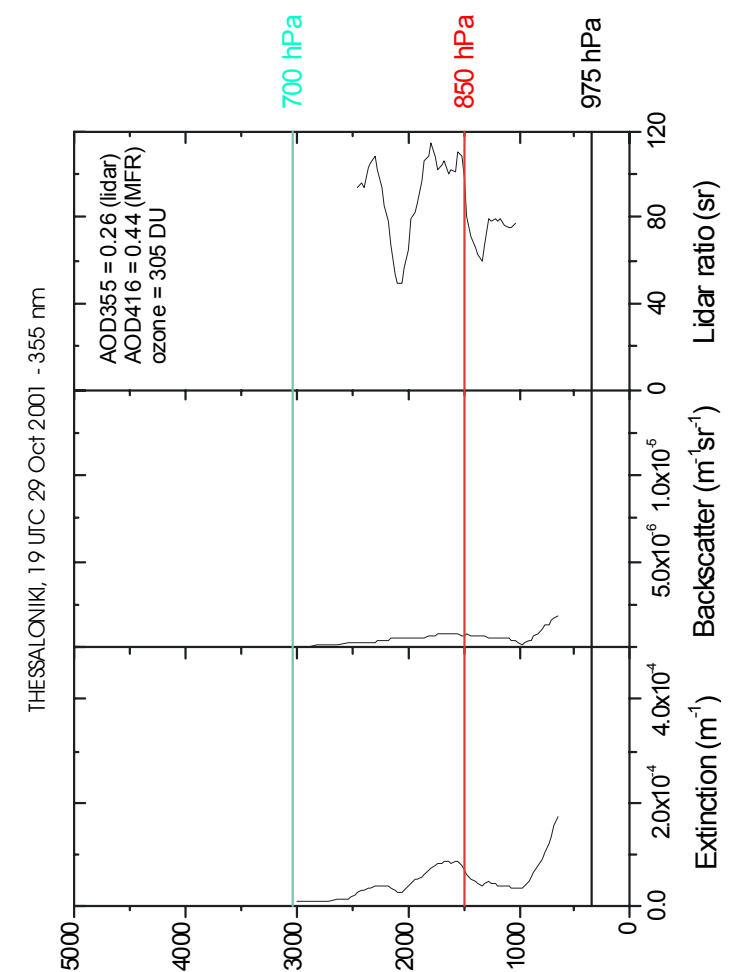

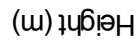

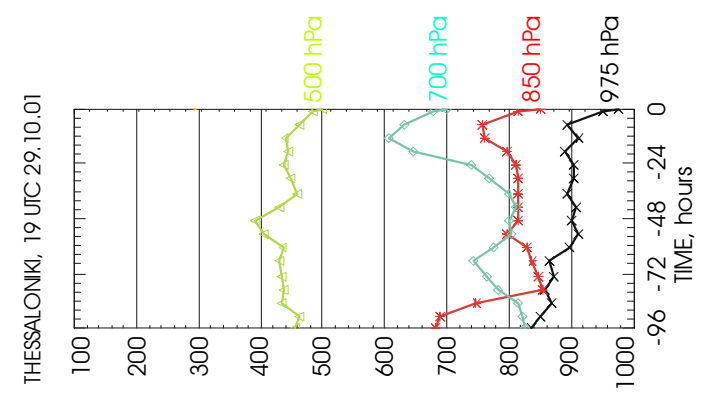

DdY ' $\exists d \cap S S \exists d d$

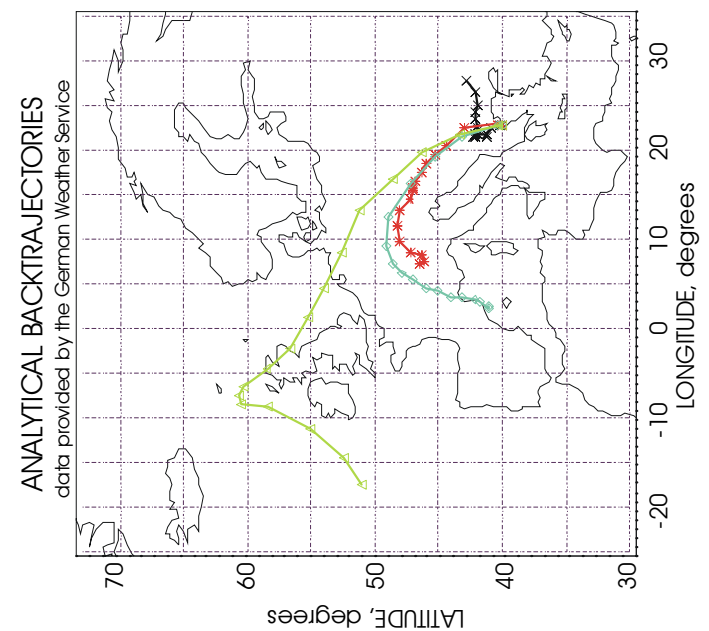

Fig. 5. Same as Fig. 4 but for 13-09-2001 and 29-10-2001. 


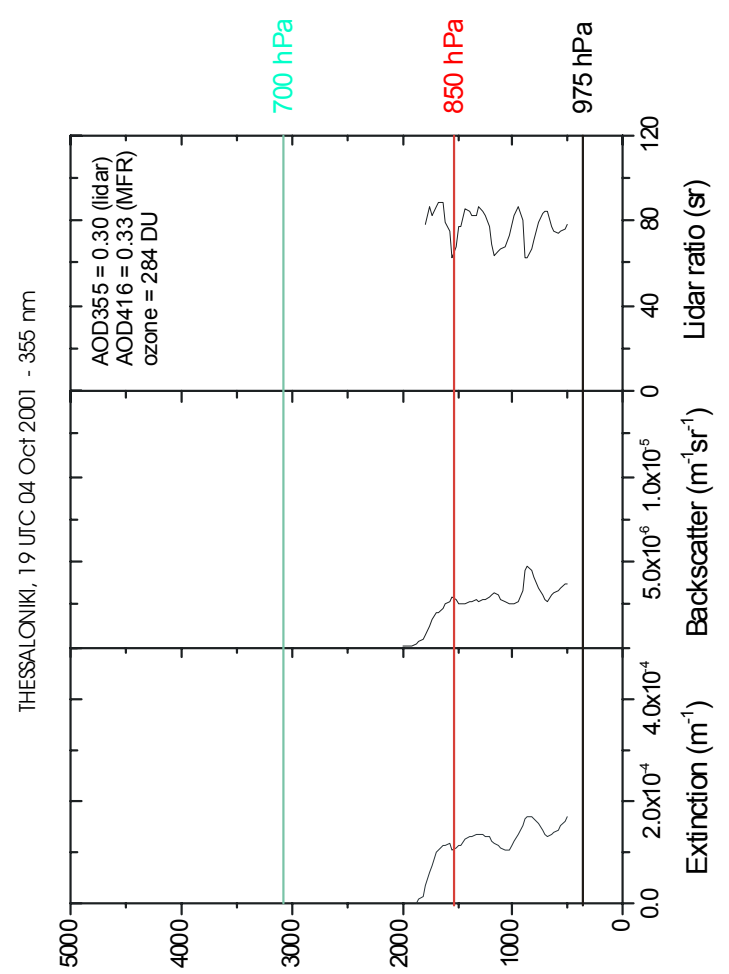

(u) 니!ㅂ
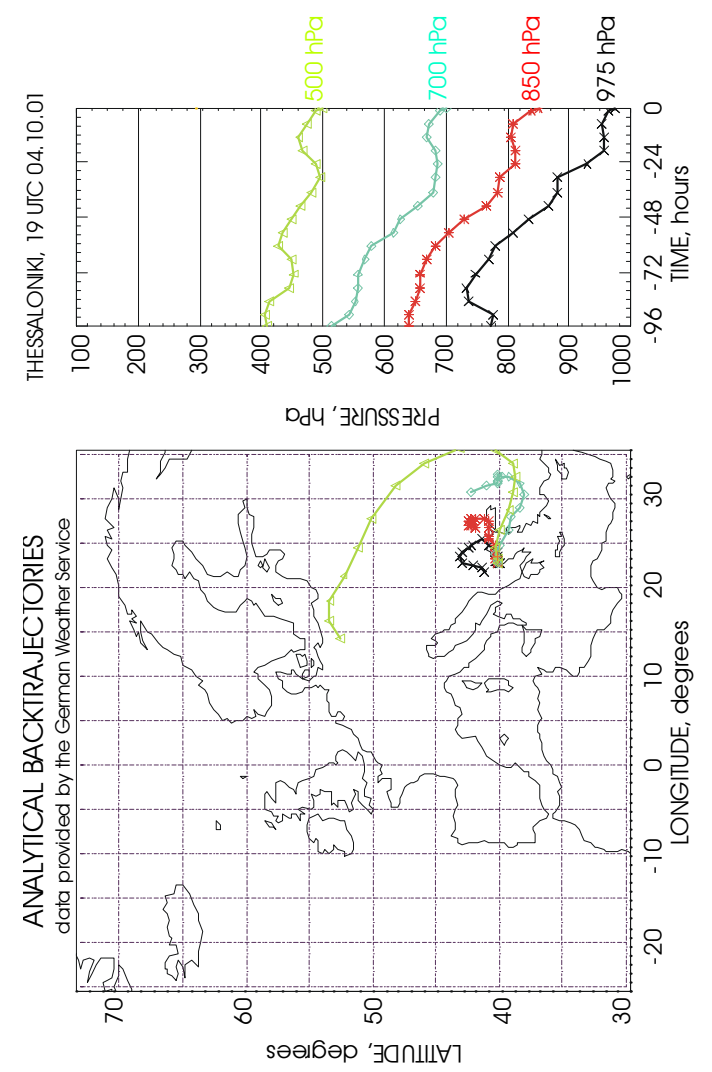

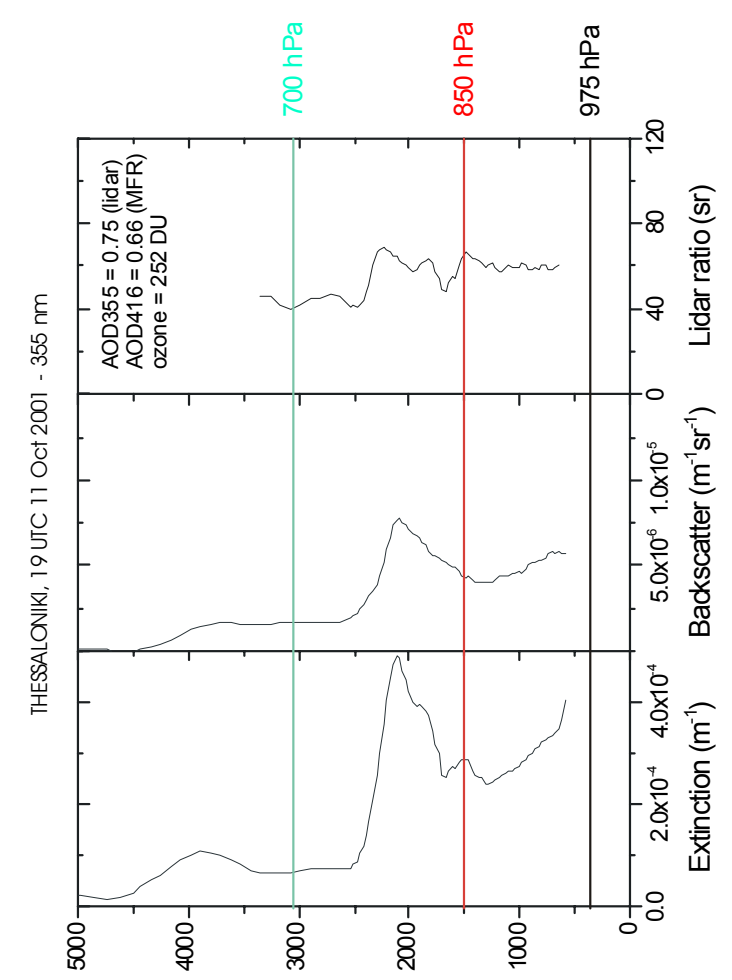

(w) 씨카

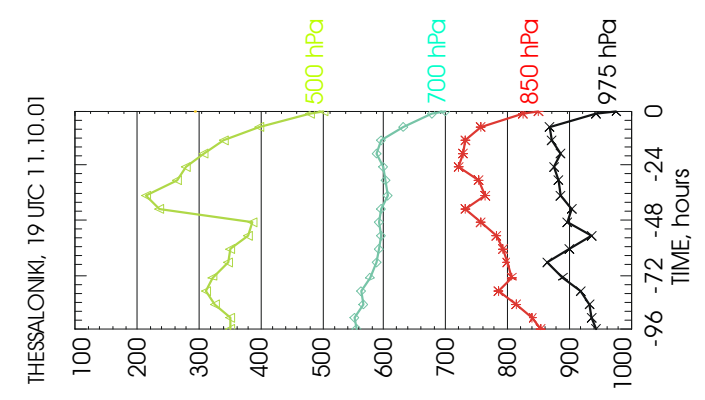

Ddu 'כynSS

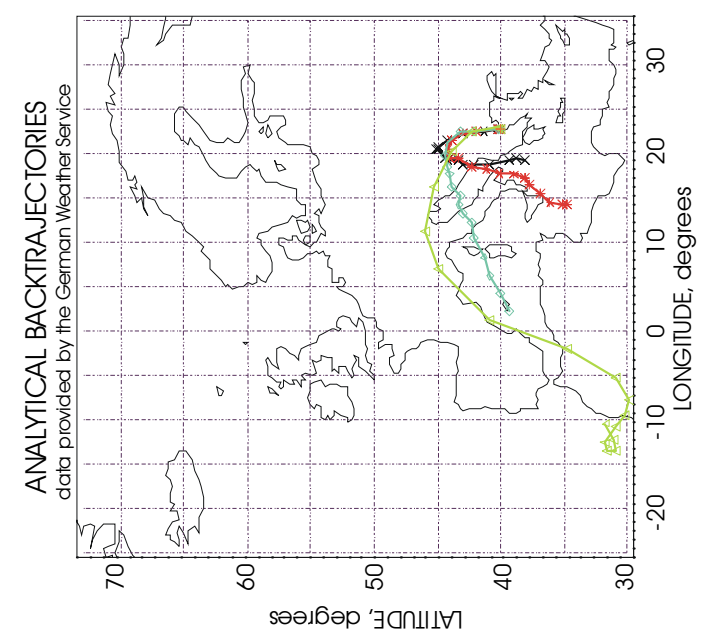

Fig. 6. Same as Fig. 4 but for 4-10-2001 and 11-10-2001. 

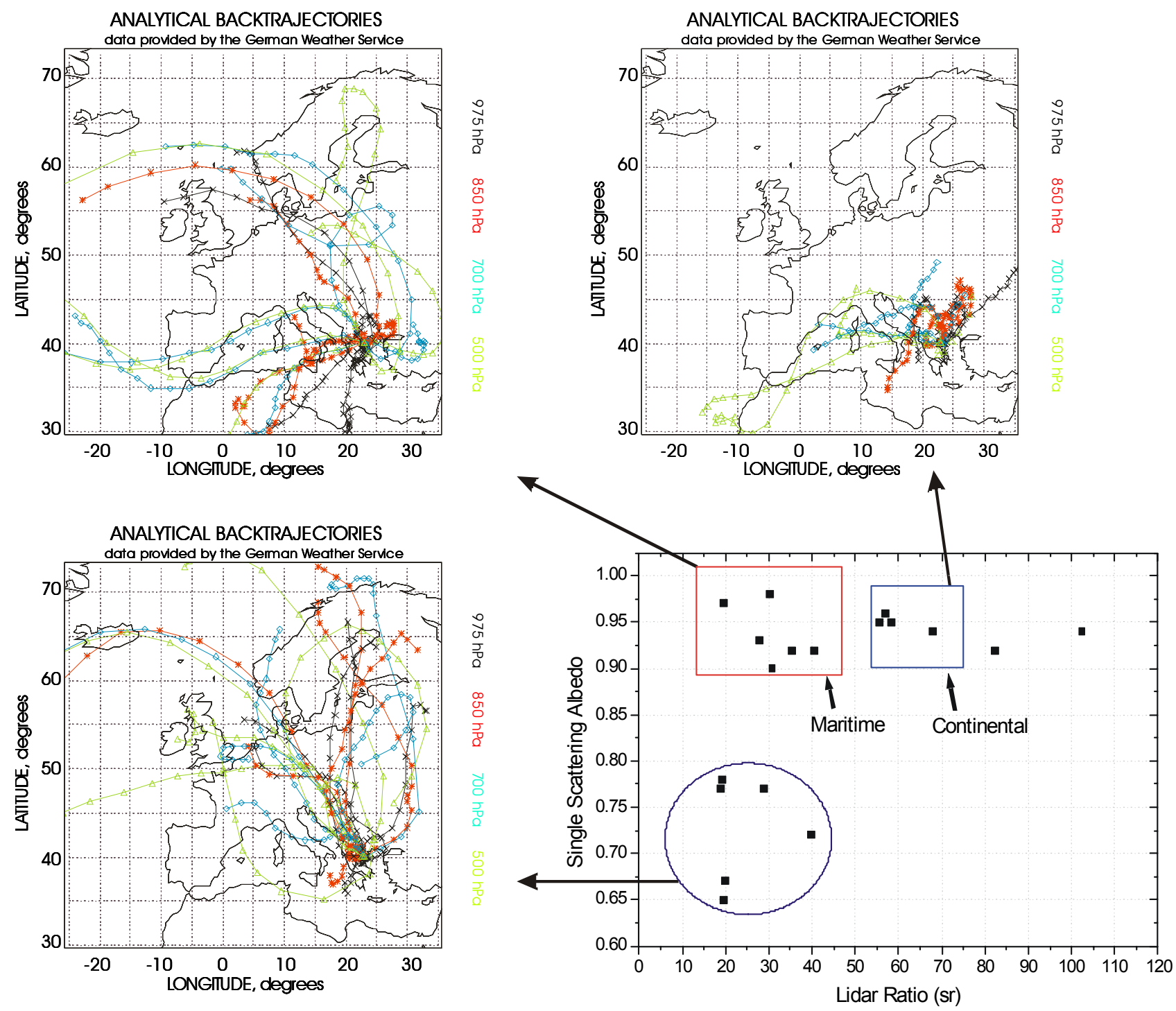

Fig. 7. Lidar ratio versus single scattering albedo as determined by measurements at Thessaloniki together with corresponding backward air trajectories.

changes in the atmosphere. Similar studies performed by Ferarre et al, using Raman lidar measurements and SSA estimations based on size distribution measurements concluded that higher SSA values correspond to lower lidar ratios, however highly dependent on relative humidity and the real part of the refractive index. Asseng et al. (2003) estimated from aircraft measurements, during a Sahara dust event, profiles of the SSA at $542 \mathrm{~nm}$, showing a strong vertical variability, low SSA values in the dust layer and higher SSA values above and below. Hensen et al. (2003) highlighted the importance of this variability in estimating the radiative forcing due to aerosols.

\section{Conclusions}

The effect of different types of aerosol on the levels of UV irradiance at the Earth's surface was examined using routine lidar measurements performed at Thessaloniki, Greece using a Raman lidar system, in the frame of the EARLINET project. For this purpose we used spectral and broadband UV-B irradiance measurements, as well as total ozone observations, whenever lidar measurements were obtained.

A methodology for the indirect determination of the SSA, using spectral UV measurements has been verified with independent measurements during LACE98.

From the available measurements during EARLINET three cases that allowed separating the impact of the various 


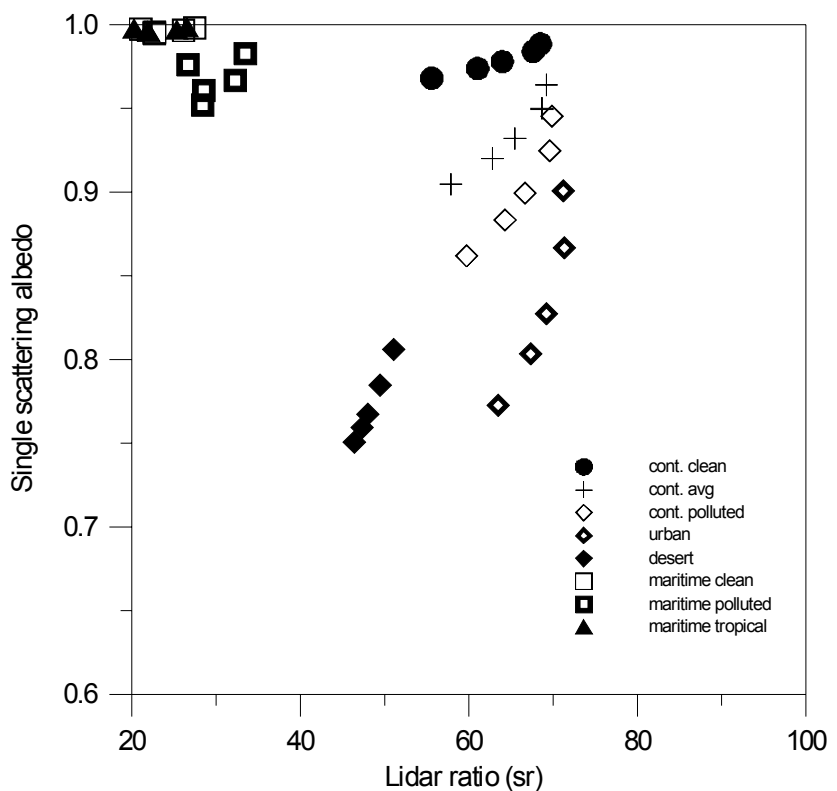

Fig. 8. Lidar ratio versus single scattering albedo as determined by the OPAC model.

parameters that control UV levels have been studied in detail. According to the analysis presented, the variability in optical depth and/or in aerosol type can introduce changes of the order of $10-25 \%$ in the UV irradiance, which can even mask changes expected from total ozone perturbations of the order of 30-50 DU.

It has been shown that the experimental determination of lidar ratio and the SSA are crucial for the interpretation of observed UV changes, especially for regions with highly variable aerosol conditions as it is the case in Northern Greece.

It has been demonstrated that the combined use of the estimated single scattering albedo and the measured extinctionto-backscatter ratio leads to a better characterization of the aerosol type probed, in the case of homogeneous aerosol layers. However as also demonstrated in this paper this is rarely the case. Therefore it is crucial to perform such measurements in parallel in order to achieve a significant amount of coincident data of SSA and LR, which will help to refine and validate the proposed approach. This information can be further used as input to radiative transfer models. In case of high aerosol load the estimated optical parameters at the Earth's surface may not be representative for the whole aerosol column.

Acknowledgements. This work was conducted in the framework of the EARLINET project EVR1-CT1999-40003 funded by the European Commission. Back trajectories for Thessaloniki were produced by the German Weather Service (DWD). We would like to thank the two anonymous referees for their valuable comments and suggestions that helped to improve the manuscript substantially.

\section{References}

Ackermann, J.: The Extinction-to-Backscatter Ratio of Tropospheric Aerosol: A Numerical Study, J. Atmos. Oceanic Technol., 1043-1050, 1998.

Ansmann, A., Wandinger, U., Wiedensohler, M. A., and Leiterer, U.: Lindenberg Aerosol Characterization Experiment 1998: Overview, J. Geophys. Res., 107, doi:10.1029/2000JD000233, 2002.

Ansmann, A., Wandinger, U., Riebesell, M., Weitkamp, C., and Michaelis, W.: Independent measurement of extinction and backscatter profiles in cirrus clouds using a combined Raman elastic-backscatter lidar, Appl. Opt., 31, 7113-7131, 1992.

Asseng, H., Fisher, J., and Ruhtz, Th.: Saharan Dust over Central Europe-Vertical profiles of an event observed by airborne optical measurements, 1st EARLINET Symposium, Hamburg, http://lidarb.dkrz.de/earlinet/earlisymp/posterlist.htm, 2003.

Bais, A. F., Kazantzidis, A., Kazadzis, S., Balis, D., Zerefos, C. S., and Meleti, C.: Effects of aerosol optical depth and single scattering albedo on surface UV irradiance, in Ultraviolet Ground- and Space-based Measurements, Models, and Effects, proceedings of SPIE, San Diego 30 July-1 August 2001, Vol. 4482, 15-22, 2002.

Bais, A. F., Kazantzidis, A., Kazadzis, S., Balis, D., Zerefos, C. S., and Meleti, C.: Deriving an effective aerosol single scattering albedo from spectral surface UV irradiance measurements, submitted to Appl. Optics, 2003.

Bais, A. F., Zerefos, C. S., Meleti, C., Ziomas, I. C., and Tourpali, K.: Spectral measurements of solar UVB radiation and its relations to total ozone, $\mathrm{SO}_{2}$, and clouds, J. Geophys. Res., 98, 5199-5204, 1993.

Balis, D., Papayannis, A., Galani, E., Marenco, F., Santacesaria, V., Hamonou, E., Chazette, P., Ziomas, I., and Zerefos, C.: Tropospheric LIDAR Aerosol Measurements and Sun Photometric Observations at Thessaloniki, Greece, Atmos. Envir., 34, 925932, 2000

Balis, D. S., Zerefos, C. S., Kourtidis, K., Bais, A. F., Hofzumahaus, A., Kraus, A., Schmitt, R., Blumthaler, M., and Gobbi,G. P. Measurements and modeling of photolysis rates during the PAUR II campaign, J. Geophys. Res., doi:10.1029/2000JD000136, 2002.

Balis, D., Amiridis, V., Zerefos, C., Gerasopoulos, E., Andreae, M., Papayannis, A., and Mamouri, R.-E.: Regional and longrange transported aerosols detected with a Raman lidar and filter radiometer measurements , 1st EARLINET Symposium, Hamburg, http://lidarb.dkrz.de/earlinet/earlisymp/posterlist.htm, 2003.

Bösenberg, J., Ansmann, A., Baldasano, J., et al.: EARLINET: A European aerosol research lidar network, Advances in Laser Remote Sensing, 20th ILRC, edited by Dabas, A., Pelon, J., and Flamant, P., 155-158, 2001.

Brühl, C. and Crutzen, P.: On the disproportionate role of tropospheric ozone as a filter against solar UV-B radiation, Geophys. Res. Lett., 16, 703-706, 1989.

Bundke, U., Haenel, G., Horvath, H., Kaller, W., Seidl, S., Wex, H., Wiedensohler, A., Wiegner, M., and Freudenthaler, V.: Aerosol optical properties during the LACE 98, doi:10.1029/2000JD000202, 2002.

Dubovik, O., Smirnov, A., Holben, B. N., King, M. D., Kaufman, Y. J., Eck, T. F., and Slutsker, I.: Accuracy assessments of 
aerosol optical properties retrieved from Aerosol Robotic Network (AERONET) Sun and sky radiance measurements, J. Geophys. Res., 105, D8, 9791-9806, 2000.

Eisinger, M. and Burrows, J. P.: Tropospheric sulfur dioxide observed by the ERS-2 GOME instrument, Geophys.Res. Lett., 25(22): 4177-4180, 1998

Ferrare, R., Melfi, S. H., Whiteman, D. N., Evans, K. D., Poellot, M., and Kaufman, Y. J.: Raman lidar measurements of aerosol extinction and backscattering, 2 Derivation of aerosol real refractive index, single-scattering albedo, and humidification factor using Raman lidar and aircraft size distribution measurements, J. Geophys. Res., 103, D16, 19673-19689, 1998.

Formenti, P., Andreae, M. O., Andreae, T. W., et al.: Aerosol optical properties and large-scale transport of air masses: Experimental observations from a coastal and a semi-arid site in the Eastern Mediterranean during summer 1998, J. Geophys. Res., 106, 9807-9826, 2001.

Gerasopoulos, E., Andreae, M. O., Zerefos, C., Andreae, T. W., Balis, D., Formenti, P., Merlet, P., Amiridis, V., and Papastefanou, C.: Climatological aspects of aerosol optical properties in Northern Greece, Atmos. Chem. Phys., 3, 2025-2041, 2003.

Haenel, G.: Optical properties of atmospheric particles: Complete sets obtained through polar photometry and an improved inversion technique, Appl. Opt., 33, 7187-7199, 1994.

Harrison, L., Michalsky, J., and Berndt, J.: Automated multifilter rotating shadow-band radiometer: an instrument for optical depth and radiation measurements, Appl. Optics, 33, 5118-5125, 1994.

Hensen, A., Brink, H., Swart, D., Bergwerff, H., and Apituley, A.: Aerosols: Closure of the radiation balance, 1st EARLINET Symposium, Hamburg, http://lidarb.dkrz.de/earlinet/earlisymp/ posterlist.htm, 2003.

Hess, M., Koepke, P., and Schult, I.: Optical Properties of Aerosols and clouds: The software package OPAC, Bull. Am. Met. Soc., 79, 831-844, 1998.

Hoyningen-Huene, W., Schmidt, T., Freitag, M., Waletrsdorf, M., and Roth, S.: Inidrekte Bestimmung der Single Scattering Albedo und des komplexen Brechungsindex des atmosphaerischen Aerosols aus kombinierten spektralen Sonnenund Himmelsstrahlung- sowie spektralen Strahlungsflussmessungen und Ermittlung des Strahlungsantriebs, Final report for FK07AF227/0, Bremen, Germany, 2001.

Kazantzidis, A., Balis, D. S., Bais, A. F., Kazadzis, S., Galani, E., Kosmidis, E., and Blumthaler, M.: Comparison of model calculations with spectral UV measurements during the SUSPEN campaign: the effect of aerosols, J. Atmos. Sci., 58, 1529-1539, 2001.

Kerr, J. B. and McElroy, C. T.: Evidence for large upward trends of ultraviolet-B radiation linked to ozone depletion, Science, 262, 1032, 1993.

Lantz, K. O., Shetter, R. E., Cantrell, C. A., Flocke, S. J., Calvert, J. G., and Madronich, S.: Theoretical, actinometric and radiometric determinations of the photolysis rate coefficient of $\mathrm{NO}_{2}$ during the Mauna Loa Observatory Experiment 2, J. Geophys. Res., 101, 14 613-14 629, 1996.

Leiterer, U., Weller, M., Urban, J., and Naebert, T.: Quality assurance of aerosol optical tchickness monitoring for the Lindenberg sunphotometer types BAS and ABAS, WMO TECO-1994, Instrum. And Obs. Methods Rep. 57, WMO/TD 588, pp. 201-206,
1994.

Lelieveld, J., Berresheim, H., Borrmann S., et al.: Global air pollution crossroads over the Mediterranean, Science, 298, 794-799, 2002.

Madronich, S.: The atmosphere and UV-B radiation at ground level, In: Environmental UV Photobiology, Plenum Press, New York, 1-39, 1993.

Matthias, V., Freudenthaler, V., Amodeo, A., et al.: Aerosol lidar intercomparison in the framework of the EARLINET project. 1. Instruments, Applied Optics, in press, 2004.

Matthias, V.: Vertikalmessungen der Aerosolextinktion und des Ozons mit einem UV-Raman lidar, Dissertation, Univ. of Hamburg, Germany, 2000.

Marenco, F., Santacesaria, V., Bais, A., Balis, D., Di Sarra, A., Papayannis, A., and Zerefos, C. S.: Optical properties of tropospheric aerosols determined by lidar and spectrophotometric measurements (PAUR campaign), Appl. Opt., 36, 6875-6886, 1997.

Mayer, B., Seckmeyer, G., and Kylling, A.: Systematic longterm comparison of spectral UV measurements and UVSPEC modeling results, J. Geophys. Res., 102(D7): 8755-8768, 1997

Papayannis, A. and Balis, D.: Study of the structure of the lower troposphere over Athens using a backscattering Lidar during the MEDCAPHOT-TRACE experiment: Measurements over a suburban area, Atmos. Envi., 32, 12, 2161-2172, 1998.

Papayannis, A., Balis, D., Bais, A., van der Bergh, H., Calpini, B., Durieux, E., Fiorani, L., Jaquet, L., Ziomas, I., and Zerefos, C. S.: The role of urban and suburban aerosols on solar UV radiation over Athens, Greece, Atmos. Envir., 32, 12, 2193-2201, 1998.

Petters, J. L., Saxena, V. K., Slusser, J. R., Wenny, B. N., and Madronich, S.: Aerosol single scattering albedo retrieved from measurements of surface UV irradiance and a radiative transfer model, J. Geophys. Res., 108 (D9), 4288, doi:10.129/2002JD002360, 2003.

Shetter, R. E., Cantrell, C. A., Lantz, K. O., Flocke, S. J., Orlando, J. J., Tyndall, G. S., Gilpin, T. M., Fisher, C. A., Madronich, S., Calvert, J., and Junkerman, W.: Actinometric and radiometric measurement and modeling of the photolysis rate coefficient of ozone to $\mathrm{O}\left({ }^{1} \mathrm{D}\right)$ during during the Mauna Loa Observatory Experiment 2, J. Geophys. Res., 101, 14 631-14 641, 1996.

Shettle, E. P. and Fenn, R. W.: Models for the aerosols of the lower atmosphere and effects of humidity variations on their optical properties, Air Force Geophys. Laboratory, Environmental Papers No. 676, 1979.

Stamnes, K., Tsay, S.-T., Wiscombe, W., and Jayaweera, K.: Numerically stable algorithm for discrete-ordinate-method radiative transfer in multiple scattering and emitting layered media, Appl. Opt., 27, 2502-2509, 1988.

Wandinger, U. and Ansmann, A.: Experimental Determination of the Lidar Overlap Profile with Raman Lidar, Appl. Opt., 41, 511514, 2001.

Weihs, P. and Webb, A.: Accuracy of spectral UV model calculations 1. Consideration of uncertainties in input parameters, J. Geophys. Res., 102, D1, 1541-1559, 1997.

Wenny, B. N., Schafer, J., DeLuisi, J., Saxena, V., Barnard, W., Petropavlovskikh, I., and Vergamini, A.: A study of regional aerosol radiative properties and effects on ultraviolet-B radiation, J. Geophys. Res., 103 (D14), 17 083-17 097, 1998. 
WMO: Scientific Assessment of Stratospheric Ozone, WMO Ozone Research and Monitoring Project, Ozone Report No. 47, Geneva, 2003.

WMO: Scientific Assessment of Stratospheric Ozone, WMO Ozone Research and Monitoring Project, Ozone Report No. 44, Geneva, 1998.

Zerefos, C. S., Balis, D., Tzortziou, M., Bais, A., Meleti, C., Bernhard, G., and Herman, J.: A Note on the Interannual Variations of UV-B erythemal doses and solar irradiance from ground-based and satellite observations, Ann. Geophys., 19, 115-120, 2001.
Zerefos, C. S., Ganev, K., Kourtidis, K., Tzortziou, M., Vasaras, A., and Syrakov, E.: On the origin of $\mathrm{SO}_{2}$ above Northern Greece, Geophys. Res. Lett., 27 (3), 365-368, 2000.

Zerefos, C. S, Meleti, C., Balis, D., Tourpali, K., and Bais, A. F.: Quasi-biennial and longer-term changes in clear sky UV-B solar irradiance, Geophys. Res. Lett., 25, 23, 4345-4348, 1998.

Zerefos, C. S., Balis, D. S., Bais, A. F., Gillotay, D., Simon, P. C., Mayer, B., and Seckmeyer, G.: Variability of UV-B at four stations in Europe, Geophys. Res. Lett., 24, 1363-1366, 1997. 